África (São Paulo, 1978, Online), São Paulo, n. 42, p. 109-122, 2021

http://dx.doi.org/

\title{
A dimensão ancestral da comunidade
}

Fabio Leite

A sociedade Senufo é organizada espacialmente em unidades comunitárias autossuficientes, as aldeias. Tratando-se de característica básica desse complexo civilizatório, torna-se necessário verificar quais instâncias ancestrais integram essas formações e qual a concretude delas na configuração de sua estrutura e dinâmica.

Não existe um consenso estabelecido entre os estudiosos da civilização Senufo quanto à época do aparecimento das aldeias, mas há concordância de que seriam os primeiros ocupantes do anual território. Holas (1957) nega que sejam autóctones e situa sua chegada à região de Korhogo no anal dó século XVI. Rougerie acredita, como vimos, que esses voltaicos começaram a ocupar tal área "no primeiro milênio de nossa era" (1977: 77), à qual teriam chegado por vagas. Coulibaly (1978) adota a tese de serem os primeiros habitantes do território, nele se fixando após movimentos migratórios ocorri dos em uma etapa da época da coleta e caça. Ouattara (1979) considera-os como os primeiros habitantes da região, oferecendo alguns dados para defender essa ideia, dos quais consideramos os mais tangíveis a ausência de relatos ligados à conquista da terra pela Força e a referência contínua, e mesmo ritual, aos ancestrais-fundadores ligados à criação dos primeiros núcleos.

De qualquer maneira, autóctones ou não, a antiguidade dos Senufo em seu território atual é reconhecida pelos autores, 'e o aparecimento das aldeias

Ouattara e Coulibaly situam em 1320 a chefia de Korhogo - espécie de capital do território Senufo -- por parte de Nanguem Soro. Os números apresentados para chefias a essa data indicam, entretanto, que existiram antes de Nanguem Soro no mínimo oito chefias e no máximo 33, estabelecendo um período de cerca de quatro a catorze séculos antes de 1320. Esse período foi calculado pela média de duração de cada chefia, 
FABIO LEITE A dimensão ancestral da comunidade

parece ter suas raízes históricas no processo de passagem à sedentarização e da opção pela agricultura como modo de produção.

Alguns etnólogos pensam que essas formas são posteriores à civilização paleonegrítica. Mas no caso que nos concerne, parece que a emergência das formas de aldeias Senufo está ligada à adoção da agricultura, se nos referirmos às modalidades de criação de uma aldeia Senufo. (Ouattara, 1979)

De fato, como vimos à fundação de um núcleo, dando origem à aldeia, ocorre basicamente quando uma família ocupa determinada área após efetivação de um pacto celebrado com a terra - devido à natureza divina desta - pelo patriarca-fundador, chefe da família então instalada. Sem esse pacto não existe possibilidade de aliança com as divindades protetoras do local e a ocupação não é legitima. $\mathrm{O}$ pacto estabelece os direitos e deveres de ocupação, gerando a primazia da exploração da terra e a possibilidade de cessão de algumas de suas partes, sem que sejam desvinculadas da área total abrangida pela aliança. Dessa forma, o aparecimento de uma aldeia Senufo tem por base as relações estabelecidas por uma família com a terra, fator de produção e elemento da autonomia da comunidade. Por outro lado, os demais agentes sociais -- mesmo outras famílias -- integrados na aldeia fundada pela família pactuante, ligam-se a esta também pela terra, na medida em que podem obter daquelas subáreas para exploração. Nessa relação estabelecida entre a família pactuante e a terra são encontrados fundamentos decisivos da configuração da aldeia, que se confunde com a problemática da ocupação da terra e dos consequentes processos de produção. Trata-se de uma relação vital existente entre a terra e o homem, nascida da sacralização estabelecida pelo pacto. ${ }^{2}$

estimada em quarenta anos cada.

2 Esse caráter gemi-divino da aldeia e a sua sacralização é confirmado ainda pelo fato de que uma aldeia somente é considerada como tal - isto é, unidade autônoma, desvinculada juridicamente de uma aldeia-matriz -, quando é chamada de Kaha (aldeia) e não de vogo (“acampamento”). Para tanto, é necessário que seja também dotada de um Bosque Sagrado devidamente sacralizado, de um panteão e de um cemitério, conforme indica Ouattara (1979). Esses elementos estão, de fato, ligados concretamente à explicação da noção de aldeia e integram a organização social dos Senufo. Ouattara considera que o Poro -- instrumento regulador dessa sociedade, enquanto corpo de normas doutrinárias - emergiu juntamente com a criação das primeiras comunidades Senufo devido à necessidade de fixar "uma prática comum estabelecendo os direitos e os deveres de cada um dos habitantes da aldeia" (Ouattara, 1979). Ora, o Poro é inseparável do Bosque Sagrado e das demais instituições sociais Senufo, sendo a autonomia de um núcleo dependente da sacralização de seu Bosque Sagrado. Enquanto isso não ocorrer, o Poro local está vinculado a outro Bosque Sagrado. O mesmo ocorre com relação aos panteões e cemitérios. Registre-se, a propósito da figura institucional dos cemitérios que, segundo um depoimento obtido de Tidiane Dem (Korhogo, 1979), quando um ancião falece fora da 
Assim, o fato de o aparecimento da aldeia emergir de um pacto selado com a terra parece confirmar que a sedentarização correspondeu à opção pela agricultura como modo de produção entre os Senufo.

Tal opção da sociedade Senufo - uma civilização agrária - permite identificar certas instâncias ancestrais e alguns aspectos não negligenciáveis da organização social desses voltaicos. Essas instâncias, no aspecto eleito para os fins deste trabalho, são essencialmente a família e a fundação da aldeia, com a manutenção e continuidade de ambas no tempo e no espaço.

Vimos anteriormente que nos processos de aparecimento das aldeias fatores básicos da organização da sociedade em núcleos autossuficientes, que envolvem a sedentarização e o modo agrícola de produção - a família ê um de seus componentes mais decisivos. Vejamos agora sua dimensão ancestral.

A célula básica da sociedade Senufo é a Nerigbaa (família extensa, descendência em sentido amplo), composta fisicamente pela família-matriz (a família do chefe da Nerigbaa), e pelas famílias conjugais - $K_{p a a}$ (casa, habitação) -, todas ligadas pelo sangue. A Nerigbaa, em termos de sua estrutura, engloba o chefe da família extensa (Nerigbaafolo) - patriarca mais velho $d a$ Nerigbaa e representante do ancestral-fundador -, sua esposa, ou esposas, e filhos; irmãos, mulheres e filhos destes; irmãs, tias e sobrinhas, solteiras ou viúvas, assim como os filhos destas últimas. Cada $K_{p a a}$ é formada pelo esposo (Kpaafolo), esposa ou esposas e respectivos filhos.

O elemento constitutivo que mais caracteriza a Nerigbaa em suas relações de parentesco é aquele formulado pelos laços uterinos de sangue. A organização da sociedade Senufo, sob esse aspecto, é matrilinear. $\mathrm{O}$ estabelecimento dessa instituição parece decorrer da necessidade histórica da plena configuração de um grupo social segundo as proposições de seus indivíduos acerca da legitimidade de parentesco; supõe-se que tenha ocorrido em época longínqua, não identificada, provavelmente em períodos de adaptação a novos territórios, sedentarização e constituição de agrupamentos, quando nasceram as primeiras aldeias. Assim,

em uma época de semi-itinerância, foi absolutamente indispensável encontrar um critério que permitisse reconhecer os seus [. . . o mais seguro dos

localidade de origem de sua família, o cadáver deve ser transportado até o cemitério respectivo e através dos caminhos habitualmente trilhados pela pessoa falecida, não obstante os percalços que o percurso possa oferecer. $\mathrm{Na}$ maior parte das aldeias visitadas, a interação entre elas e seus cemitérios era extremamente evidente. 
critérios foi aquele da consanguinidade, da descendência em linha matrilinear. A oportunidade da adoção de um tal critério pode explicar-se também pelo fato de que, constituindo-se a mulher em um capital genético, tornava-se necessário encontrar uma regra intangível, ligando de maneira indefectível sua progenitura à sua célula social original. (Coulibaly, 1978: 123)

Essa regra intangível, encontrada para instituir o parentesco uterino, decorre do fato de que para os Senufo toda criança "qualquer que seja, tem obrigatoriamente sangue de sua mãe em suas veias. Ao contrário, nada prova de que ela o tenha de seu pai" (Coulibaly, 1978: 123). Ou seja, nenhum homem pode provar que alguém seja seu filho. ${ }^{3}$ Tal princípio deu origem às descendências femininas - Neriga - encontradas no interior da Nerigbaa.

A família extensa Senufo formula-se e legitima-se pelos laços uterinos de sangue, e em sua base encontra-se uma ancestral-mulher, aquela iniciadora das descendências femininas de uma Nerigbaa, mesmo quando, eventualmente, nenhuma de suas filhas e filhos tivessem sido gerados por seu esposo. Ela é a fonte primeira do património genético que define o grupo, aparecendo assim como elemento legitimador da família extensa, englobando a Nerigbaa "todos os descendentes de uma ancestral comum" (Coulibaly, 1978: 122).

Essa formulação da Nerigbaa tendeu, entretanto, a modificar-se, sendo acrescida de outros elementos humanos. Antigos deslocamentos, decorrentes de pressões externas, dizimações em tempos de guerra, dissidências no interior de famílias, são fatores históricos que provocaram a necessidade do estabelecimento de novas alianças, a fim de fortalecer as bases sociais das comunidades com o aumento da força de trabalho. De acordo com Ouattara (1981), a Nerigbaa pode constituir-se, além dos descendentes de uma ancestral-mulher comum - fator que mantêm os princípios matrilineares da organização da família extensa - dos indivíduos pertencentes a outras descendências, dos descendentes de cativos e de pessoas pertencentes a outros complexos civilizatórios, filiados a uma aldeia em busca de cessão de terra para cultivo. ${ }^{4}$

\footnotetext{
Tal regra, nascida da origem duvidosa da paternidade, estabeleceu uma outra: o esposo de uma mulher é sempre considerado o pai de seus filhos nascidos durante a união cabendo-lhe inclusive proceder às cerimónias funerárias em caso de morte daqueles e providenciando o enterro em sua própria aldeia, ainda que a esposa esteja vivendo com outra pessoa.

4 Entre os Senufo registra-se uma forte presença dos Dioula, pertencentes ao complexo civilizatório Mandenka, que abrange também, sob esse nome, os Bambara e os Malinke.
} 
Assim, a Nerigbaa sofreu alterações substanciais, ganhando uma dinâmica diversa de sua formulação clássica. Seu alargamento permitiu a emergência de núcleos sociais mais amplos, portadores de maior força de trabalho. Essa mutação, entretanto, ocorreu segundo regras precisas que submetem as pessoas integradas às normativas ancestrais regentes das relações e instituições estruturadoras do núcleo receptor: seja qual for o número de pessoas integradas à Nerigbaa, somente a família pactuante detém os direitos de administração da terra e, assim, o de cedê-la, em parte, para a exploração de terceiros, garantindo o caráter de inapropriabilidade e indivisibilidade da terra estabelecido pela aliança celebrada pelo ancestral-fundador.

Dessa maneira, face à sua estruturação básica e à dinâmica estabelecida pela sua possibilidade de expansão, a Nerigbaa - que no sentido mais abarcante transcende o espaço físicos ${ }^{5}$ - pode ser considerada como a própria aldeia, isto é, cada aldeia Senufo é o espaço físico onde reside a família extensa, com sua organização matrilinear, parentesco de sangue e desdobramentos, detentora de todos os fatores de produção, de sua vida material e espiritual. E nesse sentido sintetizante e dinâmico que chamamos a Nerigbaa de família-aldeia. $\mathrm{Na}$ base desse processo encontra-se o núcleo fundador da comunidade, que a legitima e é legitimado pela descendência matrilinear portadora dos direitos e deveres legados pelos ancestrais, dos quais decorrem todos os outros. E por força do critério sanguíneo que o sistema organizatório sintetizado na Nerigbaa concretiza, estando sempre referido à ancestral-mulher que originou uma de suas instâncias decisivas.

Essa ancestral-mulher é a matriz geradora da família tal como concebida pela sociedade, ligada à formulação do parentesco uterino originador da organização matrilinear, único fator material aceito pelos Senufo para definir as descendências. Está também materialmente referida ao próprio aparecimento da comunidade quando se trata da ancestral-mulher da família instalada em uma determinada área após a celebração do pacto com a terra, e nesse caso, é personagem integrante dos processos de passagem dos Senufo à sedentarização e à condição de civilização agrária.

Tal conjunto de favores históricos explicam o grande respeito e a sacralização dos princípios orientadores da organização martilinear dos Senufo,

Tratando-se de descendência sanguínea, e considerando os desdobramentos possíveis da família, membros de uma Nerigbaa podem residir em outras aldeias. 
assim como o papel social da mulher, princípios esses sintetizados, em grande parte, na figura das ancestrais-mulheres. Essa sacralização do elemento feminino exterioriza-se concretamente na mulher mais idosa da Nerigbaa, conhecida e chamada por Katyeleo ou Tyeleo (mulher idosa, tia), sobre quem Ouattara afirma:

O chefe da família a consulta da mesma forma que a seus irmãos e sobrinhos. Na maioria das vezes é o seu parecer que prevalece. Por consequência, ela é muito ouvida e respeitada. Exerce funções específicas no seio da família; ocupa-se da educação moral, social e religiosa dos membros da família; tem o dever de encontrar esposas ou esposos para os membros da família; ela transmite a história social e religiosa da família. (Ouattara, 1981:41)

E, em outro escrito: "Em poucas palavras, ela tem por dever principal a conservação da Narigboa". Ela é o chefe espiritual" (Ouattara, i979). ${ }^{6}$

Essa venerável figura simboliza os princípios matrilineares que definem a família e as descendências, representa o início e a continuidade, sintetiza a dimensão ancestral da comunidade na instância dos laços uterinos de parentesco, institui a principal célula da sociedade Senufo, a Nerigbaa, vitalmente ligada à terra pelo pacto e, portanto, aos processos de produção. As Nerigbaa - com suas ancestrais-mulheres, das quais as Katyeleo das aldeias são as representantes visíveis e símbolos de suas estruturações e dinâmicas -- constituem-se em instâncias que integram vitalmente a organização social dos Senufo, sem as quais essa sociedade não poderia manifestar-se tal como existe. Essas instâncias são materialmente e historicamente ancestrais.

Uma outra dimensão ancestral que define a noção Senufo de comunidade é dada pela fundação da aldeia, sua manutenção e continuidade ao longo da história. Para apreciar quais Estores ancestrais integram essa dimensão, torna se necessário abordar ainda uma vez a configuração da Nerigbaa em suas relações com a terra e a administração da família-aldeia.

Vimos que as Nerigbaa num de seus aspectos mais fundamentais, apresentam uma dimensão ancestral estruturada pelos laços uterinos de sangue, estabelecidos a partir de ancestrais-mulheres originadoras de descendências que concretizam a família extensa e permitem sua continuidade. Mas as $\mathrm{Ne}$ rigbaa aparecem também, em sua condição de ele mentos estruturadores de

$6 \quad$ Narigboa: o mesmo que Nerigbaa 
África (São Paulo, 1978, Online), São Paulo, n. 42, p. 109-122, 2021

uma civilização agrária, como núcleos humanos pactuados com a terra. Como já foi indicado seguidamente, a terra, devido à sua natureza sagrada, não pode ser ocupada e usu6'uída sem estabelecimento de um pacto com as divindades respectivas, sendo as Nerigbaa as detentoras da aliança e, em consequência, dos direitos e deveres decorrentes.

As Nerigbaa pactuadas configuram concomitantemente com suas formulações de matrizes geradoras de descendências - unidades básicas de produção, cujas origens remontam ao seu próprio aparecimento e a sua fusão com a terra. Nesse processo, emerge a figura do ancestral-fundador, aquele patriarca-chefe de uma família, que selou uma aliança com a terra, permitindo o aparecimento da Nerigbaa como núcleo humano que ocupa um espaço físico e detém os fatores da produção. $\mathrm{O}$ ancestral-fundador sintetiza, pois, uma outra dimensão ancestral da família-aldeia, aquela do início e continuidade material da comunidade. Estabelecedor do pacto, está na origem das normas regentes da ocupação e exploração da terra, transmitindo-as às sucessivas gerações. Por tratar-se de uma civilização agrária, compreende-se que esse herói - suficientemente poderoso para descobrir uma área de terra viável, enfrentar as forças mágicas protetoras da natureza e colocá-las a favor da comunidade - tenha ganho uma condição gemi-divina e altamente sacralizada no interior da sociedade.

Nós pudemos observar diretamente as manifestações materiais dessa sacralização no âmbito da comunidade. Para a apresentação dos dados que então conseguimos, é preciso voltar à aldeia de Penyakaha e às pedras-seres que nela descobrimos e às quais já fizemos referência. A descoberta dessas pedras-seres $^{7}$ nos proporcionou a obtenção de dados que consideramos de extrema importância para a compreensão de pelo menos duas dimensões da realidade Senufo: aquela relacionada com a noção de pessoa e de vitalidade, ou força vital, integrante dos seres - já indicada -, e outra relativa ao ancestral-fundador e sua dimensão histórico-sagrada, síntese de instância precisa da configuração da comunidade.

Havíamos obtido uma informação ${ }^{8}$ segundo a qual o ancestral-fundador

\footnotetext{
A bibliografia que conhecemos sobre os Senufo não registra a existência dessas pedras e suas relações com a visão de mundo Senufo.

8 Informação fornecida por Tidiane Dem, abril de 1979. Nunca agradeceremos o suficiente a esse venerável informante por nos ter colocado na pista dessas pedras-seres.
} 
de uma aldeia seria representado por uma pedra ${ }^{9}$. A importância atribuída a esse elemento seria tão grande que existiriam pequenas comunidades que bem poderiam se aliar a outras, mais viáveis do ponto de vista económico, para melhorar as suas condições existenciais, mas que não o faziam para não mudar a pedra do local originário ou não ter de abandoná-la. Essa informação nos parecia de importância para nosso trabalho, mas as várias tentativas de descobrir a pedra e, portanto, achar uma prova empírica, revelaram-se infrutíferas: obtivemos negação formal de sua existência, alegações de desconhecimento a respeito ou respostas evasivas. Finalmente, por uma questão de sorte, a pedra foi localizada em Penyakaha e explicada pelos seus informantes. ${ }^{10}$

Penyakaha é uma pequena aldeia constituída por uma só família do subgrupo Nafara. Sua denominação vem de Penya, nome de seu fundador, e de Kaha, aldeia. Penya-kaha é, assim, a aldeia de Penya e sua autonomia é caracterizada por possuir uma economia autossuficiente, um cemitério, um bosque sagrado e santuários específicos.

Pudemos observar ali as pedras-seres já referidas, espalhadas pela aldeia, colocadas em frente às entradas das habitações ou então reunidas em um canteiro, cada uma representando uma pessoa viva. Já a pedra do ancestral-fundador encontra-se isolada, em espaço fortemente diferenciado, público ao céu aberto, mas pode passar facilmente despercebido ao estrangeiro devido à

9 Existem outros símbolos relativos aos ancestrais-fundadores. Uma modalidade é dada pelas estatuetas que os representam, geralmente colocadas no Bosque Sagrado. Reproduzem figuras de um homem portando machado, faca e amuletos, símbolos de poder e força. As vezes as cabeças são ornamentadas por um "disco" que contém animais primordiais esculpidos. Esse elemento simboliza o poder e a força.

10 Isso ocorreu em agosto de $\mathbf{1 9 7 9}$. Estávamos em território Senufo há vários dias, e a questão das pedrasseres continuava a nos preocupar, pois antevíamos a importância desse fator para melhor explicação da figura do ancestral-fundador e de suas relações com a configuração da comunidade. Entretanto, como acontecera em abril do mesmo ano, não pudéramos confirmar o dado e chegamos às pedras-seres e à pedra do ancestral-fundador por mero acaso. Ainda em território Senufo, empreendemos a viagem de retorno a Abidjan, evitando a estrada principal a fim de percorrer, ainda uma vez, as pequenas rotas secundárias que possibilitam passar pelas inesquecíveis aldeias localizadas no percurso. Ao observarmos em uma delas, Penyakaha, a existência de um cemitério na mais estreita interação com a aldeia - um dos túmulos encostava-se na parede dos fundos de uma casa e sobre ele um homem dormia, rádio de pilhas ao lado, transmitindo -, resolvemos parar. Após varias horas passadas no local, explicados os motivos gerais de nossa presença, consideramos que havia um mínimo de condições para colocar o delicado problema da pedra do ancestral-fundador. Surpreendentemente, não houve necessidade de deliberações formais, e logo a seguir tivemos acesso ao assunto de nosso interesse e suas manifestações empíricas. Deixamos registrado aqui nossos mais profundos agradecimentos aos informantes de Penyakaha que, além da extrema cordialidade, nos permitiram acesso a dados que consideramos do maior significado para este trabalho, talvez os mais importantes de todos. 
África (São Paulo, 1978, Online), São Paulo, n. 42, p. 109-122, 2021

sua disposição aparentemente aleatória das habitações. Essa pedra constitui um monumento, pois está escondida em um cone de terra de cerca de $50 \mathrm{~cm}$ de altura, ladeado por uma vasilha de barro e por uma canoa em miniatura esculpida em madeira. $\mathrm{O}$ monumento está localizado entre duas pequenas casas, construídas bem no estilo Senufo, em forma cilíndrica, com paredes de adobe e teto em palha. Essas casas não possuem portas, encontram-se separadas por alguns metros e as entradas estão voltadas uma para outra. Todos esses elementos formam um só conjunto. Vejamos o seu significado, conforme as informações obtidas na localidade.

Penya fundou sua aldeia por volta de 1750, após selar um pacto com a terra, o que permitiu a instalação da família no local. Quando faleceu, a pedra-ser que o representa foi colocada onde se encontra até hoje, guardada e cultuada pela comunidade. A vasilha de barro serve para receber água de chuva, que é apropriada pelas divindades protetoras da aldeia, as quais ali vêm para se confraternizar com o ancestral-fundador. A miniatura de canoa revela uma particularidade da personalidade e do destino de Penya: ele deveria morrer na água, mas pereceu na guerra. Assim, seus familiares vêm colocando nesse local ao longo do tempo, a pequena escultura, para que Penya possa viajar nas águas que, no país dos ancestrais, são abundantes. As casas que rodeiam o monumento foram construídas posteriormente para conforto de Penya e de Unamatye" - apresentada a nós como a principal esposa participante da fundação do núcleo -, e são consideradas as habitações desses ancestrais na aldeia. A habitação de Penya encontrava-se totalmente vazia, mas localizamos em seu interior restos de maxilares de boi e vestígios mais aparentes dos sacrifícios de sangue feitos periodicamente no local. $\mathrm{Na}$ casa de Unamatye pudemos observar alguns objetos, como cabaças, potes e cauris. A um canto, no chão, foi construído um pequeno nicho de terra, elaborado sob a forma de peixe, onde outros objetos similares estavam colocados. São os pertences rituais de Unamatye, que também é lembrada reverenciada e cultuada pela comunidade, e sobre quem existem algumas legendas famosas na aldeia. ${ }^{12}$ Nesse conjunto espacial altamente diferenciado, sacrifícios e outros

\footnotetext{
11 Não temos como escrever esse nome, a não ser da forma que mais se aproxima daquilo que ouvimos.

12 A legenda mais longa que nos foi relatada sobre Unamatye conta que há cerca de 45 anos um cavalo desconhecido apareceu na aldeia. Embora rechaçado, sempre voltava ao anoitecer. Aldeias foram consultadas, mas nenhuma reclamou a posse do animal. Tratava se, portanto, de uma manifestação mágica. Feitos os
} 
atos rituais são levados a efeito com regularidade.

A pedra em questão, entretanto, não representa apenas a memória de Penya. Ela é, de certa maneira, o próprio ancestral, pois contém parte de seu Pile, principio vital imortalidade. Essa característica é explicada e legitimada pela proposição já referida, relativa às qualidades atribuídas a certas instâncias dos componentes vitais do homem Senufo - e também das outras sociedades estudadas -, que podem se localizar e manifestar em múltiplas circunstâncias e locais, não raro ao mesmo tempo. De fato, o ancestral encontra se no espaço dos antepassados, em altares, em máscaras, no Bosque Sagrado, reencarnados, nos momentos de transe e possessão etc. Em Penyakaha, um dos locais onde se encontra seu ancestral-fundador é a pedra que descobrimos. Essa pedra é um ser vivo no qual se fundem energias da natureza e do homem. A importância atribuída à pedra-monumento de Penyakaha decorre também do fato de que, segundo explicado na ocasião, esteja ainda ligada à divindade pessoal de Penya, e integre, de certa maneira, sua personalidade profunda. Ao término da existência visível deste, tornou-se necessário erigir um santuário especialmente dedicado à divindade, em local diverso. Nós tivemos a rara oportunidade de sermos convidados a penetrar nesse espaço sagrado e fotografar seu interior ${ }^{13}$ onde sacrifícios são feitos regularmente. Além disso, um dia por semana a cada seis dias, segundo a semana Senufo - a terra não é trabalhada, em honra à divindade.

Tal conjunto de fatores explica a sacralização da pedra-monumento de Penyakaha. Ela é símbolo da memória histórica, uma espécie de marco ou pedra fundamental. Mas sua natureza é mágica, pois é dotada da vitalidade do ancestral-fundador e essa energia se confunde com a própria vitalidade da terra. Essa força não é privativa ou particularizante: localiza-se a céu aberto, em interação com os homens e a natureza; aliada de Penya - o herói estabelecedor

jogos divinatórios, ficou constatado que se tratava de um cavalo sagrado, enviado pelas divindades em honra de Unamatye, embora esta já houvesse falecido há muito tempo $\mathrm{O}$ cavalo deveria ser bem alimentado e tratado, e não podia ser cavalgado nem utilizado para qualquer serviço. Assim viveu esse cavalo em Penyakaha durante cerca de vinte anos, rodeado de respeito, sem nunca mais deixar a aldeia. Quando morreu, foi enterrado no cemitério, Junto à pequena construção que nele se encontra, abrigo das forças protetoras que velam pela entrada da aldeia que passa por esse local. Ficou-nos a dúvida se Unamatye era esposa de Penya, ou a iniciadora das descendências matrilineares da localidade, a primeira ancestral-mulher. As respostas, nesse caso, foram limitadas e evasivas.

13 Nesse aposento somente podem penetrar homens com mais de vinte anos que se encontrem em processo de iniciação. 
do pacto - e da comunidade beneficiada com a aliança. Pertence à sociedade e liga-se à energia social da própria aldeia como um todo. ${ }^{14}$ Dentro do sistema Senufo de explicação do mundo, ela é fonte de vida coletiva, uma espécie de força vital histórica concretizada materialmente na existência da aldeia e na continuidade dessa existência. A necessidade de renovação constante dessa energia é obtida pelos sacrifícios periódicos, dos quais, em certo sentido, a coletividade renasce a cada vez.

Tais proposições tornam a ideia de abandonar a pedra-monumento - o conjunto de elementos sagrados interligados nessa instância - inaceitável para os habitantes de Penyakaha, pois ela sintetiza, como eles o disseram, a unidade da família e da aldeia, a garantia de sua sobrevivência e felicidade. Seu abandono estabeleceria um rompimento irreversível entre o ancestral-fundador e os membros da aldeia. Transferi-la de local seria quebrar o pacto selado por Penya com as divindades da terra, nutridora da comunidade, rompendo-se os elos estabelecidos e perdendo-se as forças que a protegem. Em qualquer dos casos, a ordem histórico-sagrada sofreria uma ruptura, isto é, geraria um acontecimento de consequências imprevisíveis. ${ }^{15}$

O ancestral-fundador, herói semidivino e sacralizado, celebrador do pacto que uniu a sociedade à terra, é o organizador por excelência. Permitiu a concretização de um amálgama histórico-divino que define em grande parte a concepção de aldeia e comunidade, projetando no tempo e no espaço, em seus desdobramentos e continuidade, as relações e instituições sociais estabelecidas no interior dessas unidades de produção autossuficientes.

O que descobrimos em Penyakaha -- singular e profundamente humana manifestação da consciência histórica Senufo - parece constituir as provas materiais dessa proposição, a qual faz emergir outra importante dimensão da comunidade, possibilitando uma melhor apreensão dos elementos ancestrais que integram.

14 O caráter de interação homem-natureza e a dimensão eminentemente histórica da pedra-monumento, parece revelado, embora sua natureza esteja dotada de forças vitais, pela sua instalação ao ar livre. $\mathrm{O}$ aspecto sagrado de que se reveste o conjunto, que remete a instâncias de cultos e rituais diferenciais e reservados, parece manifestar-se no fato de que uma de suas partes está localizada no santuário em questão, ao quais somente certos iniciados têm acesso.

15 A quebra da ordem ancestral provoca as mais variadas consequências negativas. Calamidades, pragas, ausência ou excesso de chuva, colheitas insuficientes, doença e morte, são fatores que podem se ligar diretamente a essa circunstância. Trata-se de uma dimensão específica do pensamento negro-africano. 
Essa trama histórica ancestral, na base da qual se encontram o pacto e o ancestral-fundador, se reproduz na continuidade que propõe: de fato, nos processos de sucessão da chefia da família detentora do pacto, assumem o posto os patriarcas mais velhos da família, aqueles representantes mais legítimos do ancestral-fundador. A legitimação decorrente desses fatos torna os processos de sucessão das chefias absolutamente naturais: não existem problemas nas sucessões de chefias, o patriarca sucessor já é conhecido da comunidade. ${ }^{16}$

O patriarca-chefe, representante do ancestral-fundador, é o guardião do pacto e dos princípios ancestrais regentes da administração da família-aldeia. Dentro da organização ancestral da família extensa Senufo (a Nerigbaa), ele é o Nerigbaafolo (chefe da Nerigbaa), o Tarafolo (guardião da terra), o $\mathrm{Ke}$ guefolo (chefe da aldeia) e o Sizangafolo (principal responsável pelo Sizanga, o Bosque Sagrado). Desempenha, portanto, funções administrativas, políticas e espirituais. ${ }^{17}$ Gere os bens, é árbitro e mediador de litígios, e responsável pela conduta de qualquer dos membros da família que lidera. Seu poder é legitimado pela terra, com a qual o ancestral-fundador celebrou o pacto originário, que possibilitou sua ocupação e exploração dentro de um estatuto sagrado. Representante desse ancestral, ele é o guardião do pacto e, por isso, encontra-se habilitado a praticar a administração da terra pactuada e a estabelecer cessões de subáreas, não permitindo, porém, sua divisão, apropriação ou venda. Em sua condição de principal sacerdote do Bosque Sagrado, é figura essencial da instituição que sintetiza as principais proposições da explicação Senufo do mundo, nelas incluídos os processos de socialização. Nestes, ajuda a dar nascimento ao homem natural social proposto pela sociedade segundo os padrões ancestrais, transformando se em Kouto, a parteira mítica do Bosque Sagrado, para o qual transporta a imagem da aldeia. Está, portanto, ligado obrigatoriamente à transmissão e observância dos valores mais significativos da sociedade. Ainda mais: sendo por excelência o representante do ancestral-fundador, é depositário de conhecimentos e segredos diferenciais, o que o torna institucionalmente o principal sacerdote dos cultos a ancestrais, a quem cabe a responsabilidade de ser o mediador mais eficaz entre os vivos e os antepassados. Essa dimensão do patriarca-chefe é também essencial para explicar sua grande autoridade e o respeito a ele dedicado, pois os ancestrais se constituem, em última análise, em pontes vitais ligadas à energia social. As 
relações entre eles e a sociedade devem, portanto, ser otimizadas. ${ }^{18}$

O patriarca-chefe é, assim, elemento unificador da família-aldeia e principal mandatário da administração da comunidade, ${ }^{19}$ símbolos da legitimidade de sua existência, conferida pelo pacto, bem como da de sua continuidade. $\mathrm{Na}$ família e na aldeia, esse venerável personagem é carinhosamente conhecido e chamado por Oleo ou Sienleo (homem idoso, o tio). E aquele que se ocupa do bem-estar social como um todo. Continuador do ancestral fundador, ê agente da força histórica e mágica integrante da comunidade, que inexistiria, tal como concebida, em caso de rompimento do pacto ou ofensa grave às normas por ele estabelecidas e as quais lhe cumpre fazer observar. Dominando a possibilidade de desordem, Oleo é símbolo e fator da vida social. ${ }^{20}$ As instituições nele sintetizadas definem outra significativa instância

18 De fato, os ancestrais podem auxiliar a comunidade nos momentos difíceis, onde sua interferência é necessária para a manutenção do equilíbrio. Em contrapartida, podem também advertir ou castigar, quando as normas ancestrais não são cumpridas de maneira aceitável. Para essas interferências utilizam suas próprias forças e poderes, frequentemente aumentados por estar próximos das instâncias divinas, ou recorrem às próprias divindades.

19 Embora o patriarca-chefe reúna uma grande soma de poderes, várias instituições tendem a moderar e limitar o alcance de suas ações. Uma delas é o próprio sistema de cessões de terra, normas estabelecidas pelos pactos, que mantém sua inapropriabilidade e indivisibilidade. Assim, o patriarca-chefe não pode ir além do estabelecido por esses pactos. No âmbito da família, seu poder é moderado por um conselho constituído pelos chefes de cada família conjugal $\left(K_{p a a}\right)$, cujos pareceres precedem obrigatoriamente as decisões. Como chefe da aldeia, ouve obrigatoriamente um órgão colegiado, como indica Coulibaly: "Nenhuma questão de ordem política que interesse à comunidade pode ser resolvida fora desse Conselho. Como se vê, o poder é em realidade colegial" (Coulibaly, 1978: 107). Interessa reter ainda que os pareceres e decisões dos órgãos colegiados são baseados na doutrina e jurisprudência ancestrais, invocando se e examinando se, ao longo dos debates, as atitudes tomadas no passado em casos similares. As sessões são abertas a todos os membros da família e da comunidade, conforme as instâncias onde ocorrem, e o julgamento cabe ao conselho respectivo que examina a problemática orientando se pelas normas ancestrais. Outra instituição tendente a moderar o poder do patriarca-chefe é a regra segundo a qual a organização do trabalho da terra e o controle da estocagem e circulação dos produtos são de responsabilidade de terceiros, não podendo o patriarca interferir em suas ações. No primeiro caso, a organização do trabalho é feita por sexo e idade, segundo as tarefas a serem desenvolvidas em cada jornada. Para esse fim existe uma pessoa, Seweleo ("supervisor dos trabalhos dos campos"), que tem a total responsabilidade pelo sucesso das atividades, supervisionando, vigiando e organizando o trabalho. No segundo caso, há o Gbodounjeo ("o que penetra nos celeiros"), encarregado dos celeiros, da estocagem dos produtos coletivos, e cujas decisões o patriarca-chefe não pode contestar. Dessa forma, o patriarca-chefe aparece essencialmente como um administrador cujos poderes são significativamente moderados por várias instituições.

20 Essa dimensão de fonte de energia vital da comunidade sintetizada no patriarca-chefe está simbolizada em Penyakaha, lugar em que há canteiros onde são colocadas as pedras-seres que representam as pessoas vivas da localidade, mas que somente no canteiro do patriarca-chefe foi permitido plantar uma árvore, manifestação de vida. 
da explicação dos elementos constitutivos da família-aldeia. Essa instância também é, em nosso entender, rigorosamente material e ancestral.

No interior da família-aldeia, detentora do pacto e configuradora da comunidade agrária autossuficiente, característica básica da organização social dos Senufo, existem duas dimensões representativas de instâncias ancestrais organizadoras das práticas históricas: as ancestrais-mulheres, definidoras e legitimadoras da família, tal como concebida pela sociedade, e suas descendências, representadas por Katyeleo; e os ancestrais-fundadores, responsáveis pelo aparecimento da comunidade e das práticas materiais que a integram, representadas por Oleo. São duas dimensões complementares e inseparáveis, definindo a validade das instituições que originaram. Tal conjunto de fatores é projetado no tempo e sintetizado materialmente em Katyeleo e Oleo, detentores dos pressupostos ancestrais que mantem viva a família-aldeia. 